PAPER

\title{
Do children with developmental dyslexia have an implicit learning deficit?
}

\author{
S Vicari, A Finzi, D Menghini, L Marotta, S Baldi, L Petrosini
}

See end of article for

authors' affiliations

J Neurol Neurosurg Psychiatry 2005;76:1392-1397. doi: 10.1136/jnnp.2004.061093

.....................

Correspondence to:

Dr S Vicari, Servizio di

Neurologia e

Riabilitazione, IRCCS,

Ospedale Pediatrico

Bambino Gesù,

Lungomare Guglielmo

Marconi 36, I-00058

Santa Marinella, Rome

(ltaly); vicari@opbg.net

Received

13 December 2004

Revised version received

8 February 2005

Accepted 9 February 2005

\begin{abstract}
Objective: The purpose of this study was to investigate the effects of specific types of tasks on the efficiency of implicit procedural learning in the presence of developmental dyslexia (DD).

Methods: Sixteen children with DD (mean (SD) age $11.6(1.4)$ years) and 16 matched normal reader controls (mean age 11.4 (1.9) years) were administered two tests (the Serial Reaction Time test and the Mirror Drawing test) in which implicit knowledge was gradually acquired across multiple trials. Although both tests analyse implicit learning abilities, they tap different competencies. The Serial Reaction Time test requires the development of sequential learning and little (if any) procedural learning, whereas the Mirror Drawing test involves fast and repetitive processing of visuospatial stimuli but no acquisition of sequences. Results: The children with DD were impaired on both implicit learning tasks, suggesting that the learning deficit observed in dyslexia does not depend on the material to be learned (with or without motor sequence of response action) but on the implicit nature of the learning that characterises the tasks.

Conclusion: Individuals with DD have impaired implicit procedural learning.
\end{abstract}

A varying percentage of children have difficulty learning to read. In many of these children, the reading impairment is secondary to a global cognitive deficit, as in the case of mentally retarded individuals, such as children with Down's ${ }^{12}$ or Williams ${ }^{\prime 3}$ syndrome. However, in most instances reading disorders are observed in children with normal intelligence and no learning difficulties linked to factors such as sensory acuity deficits, neurological impairment, or socioeconomic problems. This disorder is called developmental dyslexia (DD). Its prevalence in the school population varies across countries and languages. It is higher $(4-12 \%)$ in languages characterised by non-transparent orthography, such as English, and lower (3-8\%) in those characterised by strict grapheme-phoneme correspondence, such as Italian. ${ }^{4}$

In spite of these epidemiological data, many researchers believe that DD is a linguistic disorder and, more specifically, the consequence of a phonological disorder. In fact, clinical evidence strongly supports this hypothesis (for review see Demonet $e t a l^{5}$ and Vellutino $e t a l^{6}$ ). Children with DD usually have great difficulty analysing and processing phonological characteristics of spoken words. ${ }^{78}$ Thus, for example, dyslexic children may have problems generating rhymes ${ }^{9}$ or subdividing a word into its single phonemes. ${ }^{10}{ }^{11}$ The results of recent neuroimaging studies provide further support for these findings. Indeed, adults with DD show an atypical pattern of activation in the brain regions usually involved in phonological processing. ${ }^{12-15}$

Although it is generally believed that DD is based on a phonological disorder, other hypotheses have also been advanced. In particular, several researchers consider DD to be the consequence of a disorder in visual processing. Stein et al $^{16}$ reported visual search difficulty caused by reduced ability to correctly control ocular movements. Furthermore, individuals with dyslexia are less sensitive than normal readers to some variables, such as contrast sensitivity and visual stimulus persistence. ${ }^{17}$ Consistent with these findings, functional neuroimaging studies in individuals with DD confirm the impairment in visual processing linked with the transient or magnocellular visual subsystem. ${ }^{18}$

Another hypothesis is that DD may be caused by deficits in visual attention. ${ }^{19}{ }^{20}$ Individuals with DD have been reported to have reduced ability to find a target on a confusing background ${ }^{21}$ and to have visuospatial disorders in orienting and maintaining attention on a visual stimulus. ${ }^{22}$ Impaired information processing speed has also been reported in dyslexic individuals. ${ }^{23-27}$ According to Hari and Renvall, ${ }^{28}$ this disorder is because of difficulty in quickly shifting attention from one stimulus to the next, regardless of the sensorial modality in which the stimulus is presented. In this hypothesis, the attentional slow down is also responsible for impaired phonological representation and inaccurate visual searching.

Others suggest that DD deficits might be linked to the impaired ability to acquire and automatise new cognitive procedures. Thus, the acquisition and automatisation of competencies, such as elementary articulatory and auditory skills, eye movement processing, and letter recognition may be severely compromised during development. ${ }^{29}{ }^{30}$ As a result, individuals with DD not only have difficulty reading, but also have difficulty in other functions such as gross motor coordination, balance, and speed of information processing. ${ }^{31}$

In a recent study, Vicari et $a^{32}$ explored implicit learning abilities in dyslexic individuals and similar age controls by means of a modified version of the Serial Reaction Time (SRT) task, originally developed by Nissen and Bullemer, ${ }^{33}$ and demonstrated the presence of a specific implicit learning deficit in individuals with DD. However, Kelly et $a l^{34}$ drew contrasting conclusions when investigating implicit sequence learning in dyslexic individuals by means of a modified version of the SRT task. ${ }^{35}$ Furthermore, Waber $e a^{36}$ found no evidence of an association between poor reading abilities and deficits in sequential learning in a study on a large sample of children with "heterogeneous learning problems". These

Abbreviations: ANOVA, analysis of variance; DD, developmental dyslexia; MD (test), Mirror Drawing (test); SRT, Serial Reaction Time 
conflicting results may be due to differences in methodology. Indeed, the various studies used different SRT tasks and the ages of the individuals included were also different, as were the criteria adopted to define reading disorders. Furthermore, at least in some cases, the suspicion that explicit awareness may be involved cannot be definitively excluded.

Given the complexity of this issue, we again approached it, looking at performance of individuals with DD on different implicit learning tests. Implicit memory functions include skill learning (acquisition of general task procedure with practice), learning repeated sequences of events, habit learning (stimulus-response association), repetition priming (item-specific learning), and classical conditioning. We aimed to investigate the effects of specific types of tasks on the efficiency of implicit procedural learning in the presence of DD. For this purpose, we tested individuals with DD and matched controls using two tests (the SRT test ${ }^{33}$ and the Mirror Drawing (MD) test ${ }^{37-40}$ ) in which implicit knowledge was gradually acquired across multiple trials. Although both tests analyse implicit learning abilities, they tap different competencies. The SRT task requires the development of sequential learning and little (if any) procedural learning, whereas the MD involves the establishment of fast and repetitive processing of visuospatial stimuli but no acquisition of sequences. To avoid ambiguous "heterogeneous learning problems", all individuals with DD included in the present study were clearly diagnosed as having dyslexia, based on the DSM-IV criteria. ${ }^{41}$

\section{METHODS}

\section{Participants}

A total of 32 children and adolescents participated in the study. Of these, 16 children or adolescents ( 12 boys; mean (SD) chronological age 11.6 (1.4) years) were recruited at the Children's Hospital Bambino Gesù in Santa Marinella, Italy, where they had been clinically diagnosed as having DD. The diagnosis was based on the standard exclusion criterion of children with normal or above normal intelligence (intelligence quotient (IQ) of 90 or more), without neurobehavioural, sensorial, or socioeconomic problems, whose reading abilities were at least two standard deviations below their chronological age. The mean (SD) IQ, measured by the Italian version of the Wechsler Intelligence Scale for Children-Revised, ${ }^{42}$ was 99.4 (5.4). Moreover to avoid any possible familiarity with implicit learning tasks by the participants, we did not include any children and adolescents in this study from among those already enrolled in our previous study. ${ }^{32}$

The control group consisted of 16 normal readers ( 11 boys) matched with the dyslexic group for chronological age (mean 11.4 (1.9) years) and socioeconomic level. None of the controls had difficulty reading, evidence of cognitive impairment, attention deficit, or a hyperactivity disorder.

We obtained informed consent from the children and their parents.

\section{Procedures}

The Serial Reaction Time ${ }^{33}$

The $\mathrm{SRT}^{33}$ was administered on a portable computer (Compaq LTE 5280), which controlled stimulus presentation and reaction times (RTs), and stored data online. The children sat facing the screen on which a bar with four empty squares (length $3.3 \mathrm{~cm}$ ) appeared. During the task, one of the four squares was coloured red. The children were instructed to put their left middle and index fingers on the $\mathrm{C}$ and $\mathrm{V}$ keys of the keyboard, respectively, and to put their right index and middle fingers on the $\mathrm{B}$ and $\mathrm{N}$ keys, respectively, and to press the key corresponding to the red square when it appeared on the screen. They were asked to respond as quickly and accurately as possible. When a child pressed a key the red square disappeared, and after an interval of $0.667 \mathrm{~ms}$ it appeared again in a new position. The position of red square changed according to a pseudorandom pattern or according to a pre-established sequence. Total randomness was limited to the extent that the red square could not appear in the same position twice in a row. Six blocks of 54 stimulus-response pairs were given. Although coloured (red) square presentation was random in blocks I and VI, in blocks II-V a nine item sequence (CVCNVBNCB) of stimuli was repeated six times in each block. The children were not told about the existence of the repeating pattern. To verify whether they had gained declarative knowledge of the sequence, at the end of the sixth block they were asked whether the red square presentation had a pattern or not. In addition, each child was invited to reproduce the sequence on the keyboard. The degree of declarative knowledge gained was evaluated by calculating the percentage of items in the ordered sequence correctly reproduced. There was no difference between groups in the percentage of items reproduced $(p>0.10)$. We analysed the data by computing RT and response accuracy in each trial.

\section{Reaction time}

This was calculated as latency between stimulus appearance on the screen and key pressing, regardless of the correctness of the key pressed. Whether or not the children implicitly learned the order in which the items alternated on the screen, their RTs in the ordered sequences should have gradually decreased with respect to the first random sequence and, more importantly, should have greatly increased during the last random sequence.

\section{Response accuracy}

This was evaluated as the percentage of correct key pressing during the single blocks of each trial.

\section{Mirror Drawing test ${ }^{37}$}

All the children who performed the SRT task subsequently performed the MD task by looking at the model, their hand, and the trace through a mirror that inverted the image. The apparatus consisted of a mirror $\left(35 \times 35 \mathrm{~cm}^{2}\right)$ mounted on a $5^{\circ}$ vertically orientated metallic support and a wooden support $\left(40 \times 20 \mathrm{~cm}^{2}\right)$ that prevented the children from having a direct view of the model and of their drawing movements. The task required the children to trace a line between the double outline $(0.4 \mathrm{~cm})$ of a five pointed star while they looked at the star and their hand only in the mirror. The five pointed star consisted of ten segments (each $3.5 \mathrm{~cm}$ ). A crossbar on the star perpendicular to the base of the mirror indicated the point where the drawing had to start and stop.

The children were instructed to draw the model as rapidly and accurately as possible. They had four 10 minute sessions in which they drew as many stars as they could. The first two sessions were one after the other and the third session was at least a half hour later. The final, fourth session took place on the following day to verify long term learning.

To evaluate performance, we calculated two indexes:

- speed of tracing-defined as the number of star segments traced in 10 minutes (the duration of each session)

- response inaccuracy-defined as the number of pathway line crossings. This index was computed for each star segment reproduced.

An increase in the number of segments reproduced throughout the four sessions and a decrease in the number of errors from session I to IV represented reliable measures of the occurrence of procedural learning. 


\section{Statistical analysis}

We compared metric units of each group's results with one or two way analysis of variance (ANOVA) with repeated measures. Where appropriate, post hoc comparisons were made with Tukey's test.

\section{RESULTS}

\section{Serial Reaction Time test}

Averages of the median reaction times of the two groups in the six consecutive blocks of the SRT test are shown in fig 1 . The performance of the controls was affected by the presence of an ordered item presentation sequence (one way ANOVA: $\left.F_{5,75}=6.54, \mathrm{p}<0.0001\right)$, but the response pattern of the dyslexic children was not modulated by item presentation (one way ANOVA: $F_{5,75}=1.67, \mathrm{p}=0.11$ ). We analysed these data by means of a $2 \times 6$ (group $\times$ block). The main effect of group was not significant $\left(F_{1,30}=2.04, \mathrm{p}=0.16\right)$. The block effect $\left(F_{5,150}=6.4, \mathrm{p}<0.0001\right)$ and the group $\times$ block interaction $\left(F_{5,150}=2.8, \mathrm{p}=0.02\right)$ were significant, demonstrating a different pattern of RT changes in the two groups across blocks.

Critical for the aims of the study, the two groups' RTs differed significantly (Tukey's test) passing from the fifth to the sixth block. This difference, usually considered the most reliable measure of visual-motor sequence learning, was in fact highly significant in the controls $(p=0.0002)$ but not in the dyslexic children $(p=1)$. It is worth noting that the group effect was not significant. In particular in the first experimental block, when the participants did not know anything about the task, the mean RTs of the two groups were quite similar (controls $=453.7$ and dyslexic children $=477.4$; no significant difference $(\mathrm{p}=0.98))$.

In conclusion, although the two groups did not show RT differences at the beginning of the task (block I), two different RT curves were drawn throughout the blocks. Whereas normal readers exhibited the "U shaped" learning curve usually observed in this type of task, the dyslexic children performed similarly in both randomised and ordered blocks, thus failing to exhibit a learning curve.

We also analysed response accuracy, calculated as the number of errors. A $2 \times 2$ (group $\times$ block) ANOVA showed a significant effect of the group variable $\left(F_{1,30}=5.5, \mathrm{p}<0.03\right)$, due to the larger number of errors made by the dyslexic children (mean $7.7(3.3)$ ) than the controls (mean $5.2(3.1)$ ). The type of block (random or repeated) was not significant $\left(F_{1,30}=1.2, \mathrm{p}=0.4\right)$, given the similar number of errors made in ordered or random blocks. The interaction was also nonsignificant $\left(F_{1,30}=2.2, \mathrm{p}=0.2\right)$, indicating a similar distribution of errors in the two groups passing from repeated to random blocks (fig 2).

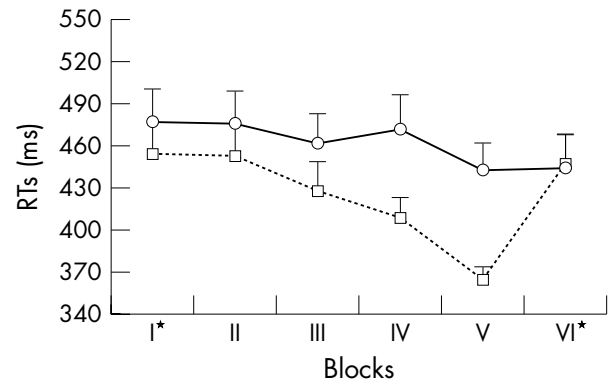

Figure 1 Reaction times (RTs) of dyslexic (circles) and control (squares) children in a task of serial learning acquisition. *Random blocks.

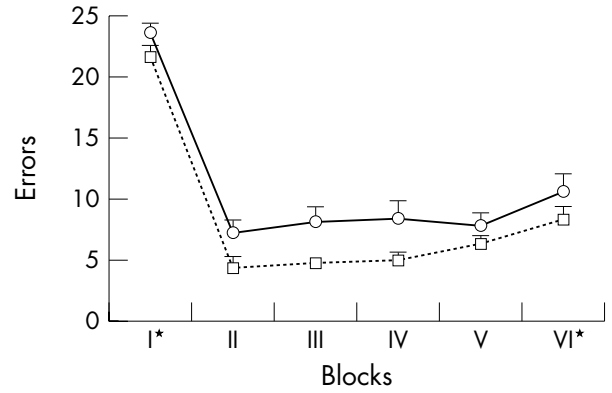

Figure 2 Errors of dyslexic (circles) and control (squares) children in a task of learning acquisition. *Random blocks.

\section{Mirror Drawing test}

The average number of elements reproduced in the four sessions by the two groups is shown in fig 3. One way ANOVAs demonstrated highly significant learning effects in both groups (controls: $F_{3,45}=16.2 ; \mathrm{p}<0.00001$; dyslexic children: $\left.F_{3,45}=76.5 ; \mathrm{p}<0.00001\right)$.

We analysed these data by means of a $2 \times 4$ (group $x$ session) ANOVA. The main effect of group was significant $\left(F_{1,30}=13.2, \mathrm{p}=0.001\right)$, with normal readers producing more elements than dyslexic children. The session effect was also significant $\left(F_{3,90}=37.1, \mathrm{p}<0.00001\right)$, as was the interaction $\left(F_{3,90}=3.2, \mathrm{p}=0.027\right)$. Post hoc comparisons demonstrated that although dyslexic children and controls produced a similar number of elements in the first, second, and third sessions (always $\mathrm{p}>0.4$ ), the former produced fewer elements than normal readers in the fourth session (mean 162.8 (51.5) and 301.1 (195.8), respectively, $\mathrm{p}=0.0001)$.

We then analysed the number of errors. Since the participants reproduced different numbers of star elements, the children who drew more segments should have made more errors (quicker but more inaccurate children). To avoid this bias, the ratio between the number of errors and the number of segments was computed for each participant in every session. The index was analysed by means of a $2 \times 4$ (group $\times$ session) ANOVA (fig 4). The main effect of group was not significant $\left(F_{1,30}=1.6, \mathrm{p}=0.2\right)$, nor was the interaction $\left(F_{3,90}=0.3, \mathrm{p}=0.8\right)$. The session effect was highly significant $\left(F_{3,90}=79.6, \mathrm{p}<0.00001\right)$.

\section{DISCUSSION}

Procedural learning is a heterogeneous phenomenon including cognitive, perceptual, motor, and other skills. Previous studies have reported variable results in individuals with dyslexia on the basis of different implicitly learned tasks. ${ }^{32} 343643$ One reason for this variability may be the

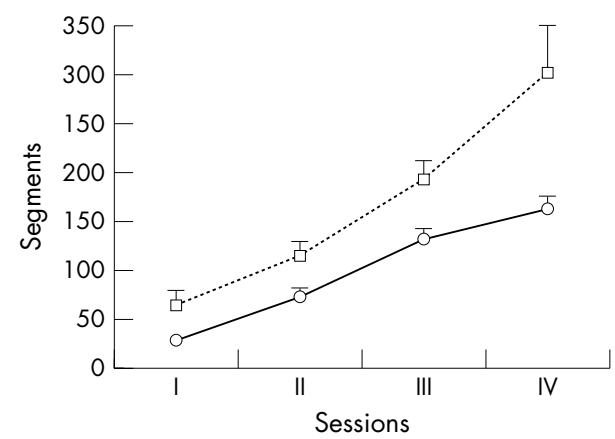

Figure 3 Number of elements reproduced by dyslexic children (circles) and controls (squares) in each session of the Mirror Drawing test. 


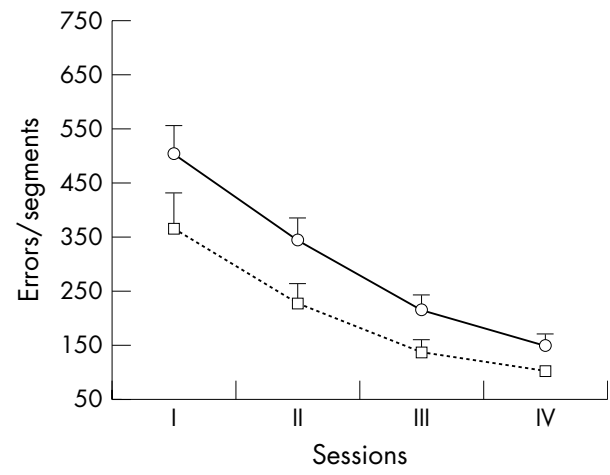

Figure 4 Ratio between number of errors and number of segments in the Mirror Drawing test.

multifaceted complexity of procedural learning, tapped differently by the demands of different tasks. Our results indicate that the children with DD were impaired on both implicit learning tasks-that is, SRT test results indicated a deficit in sequential learning in children with DD who displayed similar responses in randomised and ordered blocks. The deficit observed in the SRT task in the present study is consistent with the results obtained in a previous study, conducted in a different group of children with dyslexia, demonstrating an implicit sequential learning deficit in children with DD. ${ }^{32}$ In that study, the dyslexic children had impaired implicit learning of a visual stimuli sequence. Note that no motor sequence was demanded by the task. Conversely, the visuomotor task of the present study required implicit learning of sequential stimuli accompanied by a complex motor pattern. In this task, as well as in the previous one, only the dyslexic children showed evident deficits in the implicit knowledge of stimuli serial order. Thus, an indirect comparison between studies suggests that the learning deficit observed in dyslexic individuals does not depend on the material to be learned (with or without motor sequence of response action) but on the implicit nature of the learning characterising both tasks.

In contrast with the findings of these two studies, Kelly et $a l^{34}$ reported similar patterns of implicit learning in dyslexic and normally reading university students, although the dyslexic students had slower RTs than normal readers. However, the dyslexic individuals included in this study were university students and thus rather successful academically. It is reasonable to hypothesise some degree of recovery of the cognitive processes involved in reading in these young adults. In fact, the impact of dyslexia can be modified by the availability of resources such as semantic knowledge, ${ }^{44}$ use of context, ${ }^{45}$ visual memory, ${ }^{46}$ and verbal ability, ${ }^{47}$ which can compensate for phonological deficits. In fact, neuroimaging findings have demonstrated that a large number of ancillary systems representing the neural correlates of these compensatory processes are present in adulthood. ${ }^{48}$ Thus, it is likely that cognitive processing in children is different from that of dyslexic adults.

The SRT task adopted in a study of a large sample of children with "heterogeneous learning problems" showed no direct association between poor reading abilities and defective sequential learning. However, since the criteria for reading disorders were extremely loose, the study may have included not only individuals with dyslexia but also people affected by completely different learning disabilities.

In the MD test, although the dyslexic and normal readers made a similar number of errors ( see fig 4), the children with DD were always slower than normal readers in terms of number of segments reproduced. Even if both the groups improved as the sessions went by, we observed significant differences between the groups in the fourth session (see fig 3), which took place 24 hours after the preceding one. Behavioural studies on monkeys and humans have shown that procedural learning consists of at least two stages: an early stage and a late stage. ${ }^{49}$ Changes in learned behaviour, depending on the learning stages, and differential contribution of multiple brain areas and specific brain states, such as sleep, ${ }^{36}$ to the early and late stages have been demonstrated. $^{50} 51$ In fact, in the initial stage of learning, performance asymptotically improves, and when the training has ended, the initially formed memory trace continues to be processed. Consequently, when tested later, performance is markedly improved even without any intervening training session. This late component of learning seems to depend critically on sleep. The observation that in dyslexic individuals the influence of sleep on the late component of procedural learning is much less robust than in controls suggests different processes of consolidation of procedural abilities through off-line practice during the night. At the system level, during sleep there is an experience-dependent reactivation of cortical areas reflecting the reprocessing of elaborated information contained in the learned material. ${ }^{52} 53$ This cortical reactivation is proportional to the level of performance achieved at the end of the training session. ${ }^{54}$ By interpreting our data in line with these studies, it can be hypothesised that in the dyslexic children the experience based cortical reactivation during post-training sleep was in some way impaired. Furthermore, it cannot be excluded that the level of implicit learning achieved prior to sleep by the dyslexic children was insufficient to modulate the cortical activation during sleep.

The results of the SRT and MD tests provide evidence of reduced procedural abilities in the dyslexic children, suggesting a general deficiency of implicit learning in DD. In this regard, the reported difficulty in dyslexia to process literacy as fast as in normal readers might be considered one facet of the more general impairment in implicitly learned procedures. Actually, implicit learning abilities allow acquiring and executing new motor, perceptual, and cognitive skills, and presumably also influence reading processes, thus leading to automatisation of the mechanisms reading is based on. Further, in DD automatisation deficits may influence phonological processing and interfere with the ability to automatise elementary articulatory and auditory skills. $^{3031435556}$ In the early stages of development, implicit learning deficits may affect the maturation of successive abilities. This may explain the scattered difficulties exhibited by individuals with DD such as phonological failure, visual processing inadequacy, or attentional deficits.

We are aware that any attempt to identify the brain structures specifically involved in the implicit learning impairment displayed by the children with DD would be entirely speculative. However, it is worth noting that functional neuroimaging studies have demonstrated corti$\mathrm{cal}^{57-59}$ as well as cerebellar ${ }^{60}{ }^{61}$ and striatal ${ }^{62}$ activation during implicit sequential learning, ${ }^{62-65}$ suggesting that all these structures have a role in the implicit acquisition of sequential information. The involvement of neuronal loops comprising the basal ganglia and cerebellum, ${ }^{49}$ the former for reward based evaluation and the latter for timing processing, has been proposed. It has been reported that the anterior striatum and the putamen are related to the acquisition of sequential learning and memory storage, respectively. ${ }^{66}$ The restructuring of neural response patterns of striatal neurones occurs as a result of procedural learning, culminating in task related activity emphasising the beginning and the end of the automatised procedure. ${ }^{67}$ Experimental data support the 
involvement of cerebellar circuits in the acquisition of spatial procedural competencies. ${ }^{68-70}$

Interestingly, the changes in activity in both the striatum and the cerebellum have been observed at different stages of motor sequential learning. The cerebellum has been considered as the structure that detects and corrects the errors ${ }^{71}$ mostly made in the initial stages to adjust movement to incoming sensory input and to produce accurate motor output. $^{72}$ Conversely, striatal activation increases with practice reaching its maximum once learning is achieved. ${ }^{74}$ In this framework, striatal regions are critical for the long term storage of well learned movements. ${ }^{74} 75$

According to the clinical, experimental, and behavioural findings reported above, the procedural learning difficulties observed in individuals with dyslexia suggest that cerebellar and striatal activities are impaired. Rae et $a l^{76}$ demonstrated biochemical and morphological abnormalities in the cerebellar areas of dyslexic adults. In a positron emission tomography study on dyslexic adults, Nicolson et al ${ }^{30}$ described abnormal cerebellar activation in response to both learned and novel motor sequential tasks. In a functional magnetic resonance imaging study, Georgiewa et al ${ }^{77}$ documented a lower level of putamen activation in dyslexic children than in controls, hypothesising greater familiarity of the latter with reading performances and reduced retrieval of implicit knowledge in the former. In the light of the present findings, the possible role of striatal and cerebellar areas in the process of reading acquisition is intriguing and worthy of further investigation.

Finally, the present data suggest that evaluation of procedural abilities is a useful clinical approach for studying this developmental disorder. In fact, since procedural learning is acquired at the early stages of development, ${ }^{78}$ a deficit in the acquisition of procedural competencies may be a sign of future reading difficulty in pre-school children.

\section{Authors' affiliations}

S Vicari, A Finzi, D Menghini, L Marotta, S Baldi, IRCCS, Children's Hospital "Bambino Gesù", Santa Marinella, Rome, Italy

L Petrosini, IRCCS, Santa Lucia Foundation; Department of Psychology, University of Rome "La Sapienza", Rome, Italy

Competing interests: none declared

\section{REFERENCES}

1 Fowler A. Linguistic variability in persons with Down syndrome. In: Nadel L, Rosenthal D, eds. Down Syndrome: Living and Learning in the Community. New York: Wiley, 1995:121-31

2 Fletcher H, Buckley S. Phonological awareness in children with Down syndrome. Downs Syndr Res Pract 2002;8:11-18.

3 Menghini D, Verucci L, Vicari S. Reading and phonological awareness in Williams Syndrome. Neuropsychology 2004; 18:29-37.

4 Lindgren DS, De Renzi E, Richman LC. Cross-national comparison of developmental dyslexia in Italy and the United States. Child Dev 1985;56:1404-17.

5 Demonet JF, Taylor MT, Chaix Y. Developmental dyslexia. Lancet 2004; 363:1451-60

6 Vellutino FR, Fletcher JM, Snowling MJ, et al. Specific reading disability (dyslexia): What have we learned in the past four decades? J Child Psychol Psychiatry 2004;45:2-40.

7 Snowling M. Dyslexia: A cognitive developmental perspective. Oxford: Basil Blackwell, 1987

8 Snow C, Burns M, Griffin P. Preventing reading difficulties in young children Washington DC: National Academy Press, 1998.

9 Bradley L, Bryant PE. Categorising sounds and learning to read: a causal connection. Nature 1983;301:419-21.

10 Pennington BF, Orden GCV, Smith SD, et al. Phonological processing skills and deficits in adults dyslexics. Child Dev 1990;61:1753-78.

11 Shaywitz S. Current concepts: dyslexia. N Engl J Med 1998;338:307-12.

12 Paulesu E, Demonet JF, Fazio F, et al. Dyslexia: cultural diversity and biological unit. Science 2001;291:2165-7.

13 Paulesu E, Frith U, Snowling $M$, et al. Is developmental dyslexia a disconnection syndrome? Evidence from PET scanning. Brain 1996;119:143-57.

14 Brunswick N, McCrory E, Price CJ, et al. Explicit and implicit of words and pseudowords by adult developmental dyslexics: a search for Wernicke's wortschatz? Brain 1999;122:1901-17.
15 Demb JB, Poldrack RA, Gabrieli JDE. Functional neuroimaging of word processing in normal and dyslexic readers. In: Klein R, Mc Mullen P, eds. Converging methods for understanding reading and dyslexia. Cambridge: MIT Press, 1999:243-304.

16 Stein JF, Talcott J. Impaired neuronal timing in developmental dyslexia: the magnocellular hypothesis. Dyslexia 1999;5:56-77.

17 Lovegrove WJ. Weakness in the transient visual system: a causal factor in dyslexia. In: Tallal P, Galaburda AM, eds. Temporal information processing in the nervous system: special reference to dyslexia and dysphasia. New York: New York Academy of Sciences, 1993:57-69.

18 Eden GF, Zeffiro TA. Neural systems affected in developmental dyslexia revealed by functional neuroimaging. Neuron 1998;21:279-82.

19 Ackerman PT, Dykman RA, Gardner MT. ADD students with and without dyslexia differ sensitivity to rhyme and alliteration. J Learn Disabil 1990;23:279-83

20 August GJ, Garfinkel BD. Comorbility of ADHD and reading disability among clinically referred children. J Abnorm Psychol 1990;18:29-45.

21 Casco C, Tressoldi P, Dellantonio A. Visual selective attention and reading efficiency are related in children. Cortex 1998;34:531-46.

22 Facoetti $A$, Paganoni $P$, Turatto $M$, et al. Visual-spatial attention in developmental dyslexia. Cortex 2000;36:109-23.

23 Tallal P, Miller S, Fitch RH. Neurobiological basis of speech: a case for the preeminence of temporal processing. In: Tallal P, Galaburda AM, Llinas R, et al. Temporal Information Processing in the Nervous System, with Special Reference to Dyslexia and Dysphasia. New York: New York Academy of Sciences, 1993:27-47.

24 Tallal P. Auditory temporal perception, phonics and reading disabilities in children. Brain Lang 1980;9:182-98.

25 Temple E, Poldrack RA, Protopapas A, et al. Disruption of the neural response to rapid acoustic stimuli in dyslexia: evidence from functional MRI. Proc Natl Acad Sci U S A 2000;97:13907-12.

26 Laasonen M, Service E, Virsu V. Temporal order and processing acuity of visual auditory and tactile perception in developmentally dyslexic young adults. Cogn Affect Behav Neurosci 2001;1:394-410.

27 Laasonen M, Tomma-Halme J, Lahti-Nuuttila P, et al. Rate of information segregation in developmentally dyslexic children. Brain Lang 2000;75:66-81.

28 Hari R, Renvall H. Impaired processing of rapid stimulus sequences in dyslexia. Trends Cogn Sci 2001;12:525-632.

29 Fawcett AJ, Nicolson RI, Dean P. Impaired performance of children with dyslexia on a range of cerebellar tasks. Ann Dyslexia 1996;46:259-83.

30 Nicolson RI, Fawcett AJ, Berry EL, et al. Association of abnormal cerebellar activation with motor learning difficulties in dyslexic adults. Lancet 1999;353:1662-7

31 Nicolson RI, Fawcett AJ. Automatiticity: a new framework for dyslexia research? Cognition 1990;35:159-82.

32 Vicari S, Marotta L, Menghini D, et al. Procedural learning deficit in children with developmental dyslexia: evidence for cerebellar involvement in reading? Neuropsychologia 2003;41:108-14.

33 Nissen MJ, Bullemer P. Attentional requirements of learning: evidence from performance measures. Cogn Psychol 1987;19:1-32.

34 Kelly SW, Griffiths S, Frith U. Evidence for implicit sequence learning in dyslexia. Dyslexia 2002;8:43-52.

35 Mayr U. Spatial attention and implicit sequence learning: evidence for independent learning of spatial and nonspatial sequences. J Exp Psychol Learn Mem Cogn 1996;22:350-64.

36 Waber DP, Marcus DJ, Forbes PW, et al. Motor sequence learning and reading ability: is poor reading associated with sequencing deficit? J Exp Child Psychol 2003;84:338-54.

37 Starch D. A demonstration of the trial and error method of learning. Psychol Bull 1910;7:20-4.

38 Whipple G. Manual of mental and physical tests. Baltimore, MD: Warwick \& York, 1921.

39 Marks R. Ipsilateral and contralateral skill acquisition following random practice of unilateral mirror-drawing. Percept Mot Skills 1996;83:715-22.

40 Desmond J, Fiez J. Neuroimaging studies of the cerebellum: language, learning and memory. Trends Cogn Sci 1998;2:355-62.

41 American Psychiatric Association. Diagnostic and statistical manual of mental disorders, 4th edition (DSM-IV). Washington, DC: American Psychiatric Association, 1994.

42 Orsini A. WISC-R. Contributo alla taratura italiana. Firenze: Organizzazioni Speciali, 1993.

43 Nicolson RI, Daum I, Schugens MM, et al. Eyeblink conditioning indicates cerebellar abnormality in dyslexia. Exp Brain Res 2002;143:42-50.

44 Snowling M, Bishop D, Stothard S. Is preschool language impairment a risk factor for dyslexia in adolescence? J Child Psychol Psychiatr 2000;41:597-600.

45 Nation K, Snowling M. Individual differences in contextual facilitation. Child Dev 1998:69:996-1011.

46 Campbell R, Butterworth B. Phonological dyslexia and dysgraphia in a highly literate subject: a developmental case with associated deficits of phonemic processing and awareness. Q J Exp Psychol A 1985;37:435-75.

47 Torgesen J, Alexander A, Wagner R, et al. Intensive remedial instruction for children with severe reading disabilities: immediate and long-term outcomes from two instructional approaches. J Learn Disabil 2001;33:192-99.

48 Shaywitz SE, Shaywitz BA, Pugh KR, et al. Neural system for compensation and persistence: young adult outcome of childhood reading disability. Biol Psychiatry 2003;54:25-33.

49 Hikosaka O, Nakahara H, Rand MK, et al. Parallel neural networks for learning sequential procedures. Trends Neurosci 1999;22:464-71. 
50 Miyachi S, Hikosaka O, Lu X. Differential activation of monkey striatal neurons in the early and late stages of procedural learning. Exp Brain Res 2002; 146:122-6.

51 Maquet $\mathbf{P}$, Laureys $S$, Peigneux $P$, et al. Experience-dependent changes in cerebral activation during human REM sleep. Nat Neurosci 2000;3:831-6.

52 Sakai K, Hikosaka O, Miyauchi S, et al. Transition of brain activation from frontal to parietal areas in visuomotor sequence learning. J Neurosci 1998; 18:1827-40.

53 Peigneux $\mathrm{P}$, Laureys S, Fuchs $\mathrm{S}$, et al. Learned material content and acquisition level modulate cerebral reactivation during posttraining rapid-eyemovements sleep. Neuroimage 2003;20:125-34.

54 Gomez Beldarrain M, Grafman J, Pascual-Leone A, et al. Procedural learning is impaired in patient with prefrontal lesion. Neurology 1999;52:1853-60.

55 Nicolson R, Fawcett A. Long-term learning in dyslexic children. Eur J Cogn Psychol 2000;12:357-93.

56 Moores E, Nicolson R, Fawcett A. Attentional deficits in dyslexia: evidence for an automatisation deficit. Eur J Cogn Psychol 2003; 15:321-48.

57 Perani D, Bressi S, Cappa SF, et al. Evidence of multiple memory systems in the human brain. A [18F] FDG PET metabolic study. Brain 1993:116:903-19.

58 Dagher A, Owen AM, Boecker H, et al. Mapping the network for planning: a correlational PET activation study with the Tower of London task. Brain 1999; 122:1973-87.

59 Petersen SE, van Mier H, Fiez JA, et al. The effects of practice on the functional anatomy of task performance. Proc Natl Acad Sci U S A 1998:95:853-60.

60 Braitenberg V, Heck D, Sultan F. The detection and generation of sequences as a key to cerebellar function: experiments and theory. Behav Brain Sci 1997;20:229-45.

61 Jackson PL, Lafleur MF, Malouin F, et al. Functional cerebral reorganization following motor sequence learning through mental practice with motor imagery. Neuroimage 2003;20:1171-80.

62 Peigneux P, Maquet P, Meulemans T, et al. Striatum forever, despite sequence learning variability: a random effect analysis of PET data. Hum Brain Mapp 2000;10:179-94.

63 Doyon J, Laforce R, Bouchard JP, et al. Role of the striatum, cerebellum and frontal lobes in the automatization of a repeated visuomotor sequence of movements. Neuropsychologia 1998;36:625-41.

64 Rauch SL, Whalen PJ, Savage CR, et al. Striatal recruitment during an implicit sequence learning task as measured by functional magnetic resonance imaging. Hum Brain Mapp 1997;5:124-32.
65 Squire LR. Declarative and no declarative memory: multiple brain systems supporting learning and memory. J Cogn Neurosc 1992;4:232-43.

66 Miyachi S, Hikosaka O, Miyashita K, et al. Differential roles of monkey striatum in learning of sequential hand movement. Exp Brain Res 1997; 115:1-5.

67 Jog MS, Kubota Y, Connolly Cl, et al. Building neural representations of habits. Science 1999;286:1745-9.

68 Petrosini L, Molinari M, Dell'Anna ME. Cerebellar contribution to spatial event processing: Morris water maze and T-maze. Eur J Neurosci 1996;8:1882-96.

69 Mandolesi L, Leggio MG, Graziano A, et al. Cerebellar contribution to spatial event processing: involvement in procedural and working memory components. Eur J Neurosci 2001;14:2011-22.

70 Hazeltine E, Grafton ST, Ivry R. Attention and stimulus characteristics determine the locus of motor-sequence encoding A PET study. Brain 1997; 120:123-40.

71 Imamizu H, Miyauchi S, Tamada T, et al. Human cerebellar activity reflecting an acquired internal model of a new tool. Nature 2000;403:192-5

72 Flament D, Ellermann J, Kim SG, et al. Functional magnetic resonance imaging of cerebellar activation during the learning of a visuomotor dissociation task. Hum Brain Mapp 1996;4:210-26.

73 Doyon J, Song AW, Karni A, et al. Experience-dependent changes in cerebellar contributions to motor sequence learning. Proc Natl Acad Sci U S A 2002;99: 1017-22.

74 Grafton S, Woots R, Tyszka M. Functional imaging of procedural motor learning: relating cerebral blood flow with individual subject performance. Hum Brain Mapp 1994;1:221-34.

75 Rae C, Harasty JA, Dzendrowskyj TE, et al. Cerebellar morphology in developmental dyslexia. Neuropsychologia 2002;40:1285-92.

76 Rae C, Lee MA, Dixon RM, et al. Metabolic and abnormalities in developmental dyslexia detected by ${ }^{1} \mathrm{H}$ magnetic resonance spectroscopy. Lancet 1998;351:1849-52.

77 Georgiewa P, Rzanny R, Hopf JM, et al. fMRI during word processing in dyslexic and normal reading children. Neuroreport 1999;10:3459-65.

78 Thompson LA, Gomez RL, Schvaneveldt RW. The salience of temporal cues in the developing structure of event knowledge. Am J Psychol 2000;113:591-620. 